\title{
The Usage of Ultrasound in Diagnosing Retrocaval Ureter
}

\author{
Kimassoum Rimtebaye ${ }^{1 *}$, Herve Edouard Moby Mpah², Franklin Danki Silong3, \\ Arya Zarif Agah Tashkand1, Miangnal Kaboro', Lamine Niang', Serigne Magueye Gueye ${ }^{4}$
}

\author{
${ }^{1}$ Hôpital Général de Reference Nationale, N’Djaména, Tchad \\ ${ }^{2}$ Hôpital Laquintinie, Douala, Cameroun \\ ${ }^{3}$ Hôpital Protestant de N'Gaoundéré, N’Gaoundéré, Cameroun \\ ${ }^{4}$ Hôpital Général Grand Yoff, Dakar, Senegal \\ Email: *melinarim@yahoo.fr
}

How to cite this paper: Rimtebaye, $\mathrm{K}$. Mpah, H.E.M., Silong, F.D., Tashkand, A.Z.A., Kaboro, M., Niang, L. and Gueye, S.M. (2017) The Usage of Ultrasound in Diagnosing Retrocaval Ureter. Open Journal of Urology, 7, 212-218.

https://doi.org/10.4236/oju.2017.711025

Received: October 14, 2017

Accepted: November 14, 2017

Published: November 17, 2017

Copyright (C) 2017 by authors and Scientific Research Publishing Inc. This work is licensed under the Creative Commons Attribution International License (CC BY 4.0).

http://creativecommons.org/licenses/by/4.0/

\begin{abstract}
Introduction: Retrocaval ureter is a rare congenital anomaly concerning the inferior vena cava and the ureter, where the infra-renal segment of the vena cava is in front of the ureter embryologically normal. This anomaly is more frequent in the male sex. Its symptoms are dominated by right lumbar pain, which is managed surgically as dictated by its intensity. Observations: The cases involved three male patients aged 42 years, 38 years and 39 years respectively. These patients had consulted for intermittent right lumbar pain similar to that of renal colic. The patients' general condition was satisfactory. Renal function was normal. Urinary tract ultrasound, IVU and scanning were the main imagery examinations used in diagnosing retrocaval ureter, confirmed by exploratory lumbotomy. Ureteral anastomosis in front of the vena cava was carried out in the 3 patients during simple surgical procedure that resulted in disappearance of the lumbar pain. Conclusion: Retrocaval ureter is a rare congenital malformation, often encountered in the male sex. Clinical symptoms are dominated by right lumbar pain similar to renal colic. Surgical treatment is dictated by the intensity of the pain.
\end{abstract}

\section{Keywords}

Ureter, Vena Cava, Embryology, Renal Colic, Laparoscopy

\section{Introduction}

Retrocaval ureter was first described in 1893 by Hochstetter [1], as a rare congenital anomaly concerning the inferior vena cava and the ureter whereby the infrarenal segment of the vena cava is located behind the embryologically nor- 
mal ureter [2] [3] [4]. The incidence is 0.9 to 2 per 1000 with a male-dominated predominance, corroborated by a sex ratio ranging from 2.8 to 4 per various studies [2] [3] [4] [5]. Retrocaval ureter is usually associated with a certain degree of ureteral obstruction. It is mainly manifested by pain in the right flank (except in the case of situs inversus, infection of the urinary system and renal lithiasis) given the increasing number of complications, it is mostly treated by surgical intervention. Ureteral obstruction usually leads to functional deterioration of the kidney in adulthood. Treatment is dictated by presented symptoms, while surgical procedure needs to be conservative as possible. When available, laparoscopy could be a better replacement to surgery due to its less invasive character. As observed in the three cases of retrocaval ureter and by some authors, emphasis is placed on the importance of medical imaging in the diagnostic procedure, and adequate management of the anomaly [2] [3] [4] [5].

\section{Patients and Method: Observations}

\section{Observation 1}

M. B., 38 years old, had been suffering from an intermittent right lumbar pain for 6 years similar to renal colic, in the absence of digestive or urinary signs. This pain was the subject of several unsuccessful consultations and medical treatments. The patient was later on referred to the urology department by a colleague. On examination, his general condition was stable, palpation awakened pain at the upper right ureteral region in the absence of a lumbar mass, causing lumbar contact, renal function, in particular serum creatinine and urea, was normal. Two ultrasound examinations, one during the painful crisis and another away from the renal colic-like crisis reported two different results. One was normal (absence of dilatation) for the ultrasound performed during the crisis and a pyelocalic dilation for the other one carried out during the painful crisis. The UIV revealed: pyeloureteral junction syndrome (PUJS) as seen in the images with the contrasting product stopping at the level of the third lumbar vertebra (L3) in reverse S [Figure 1] lithiasic obstruction was absent, on the profile, with a shift in the image of the ureteric contrast at L3. Persistence of symptoms despite a well-conducted medical treatment and good compliance, led to the conduction of an exploratory lumbotomy, after patient's informed consent obtained for the chirurgical management and the using of photographies only for scientific aim. During the surgery, we located a voluminous pyelon with multiple adhesions, suggesting retroperitoneal fibrosis. We then proceeded to adenolyse from the pyelon to the lumbar ureter which suddenly disappeared behind the vena cava to reappear in front it, enabling us present our diagnosis as type II retrocaval ureter [Figure 2]. After having lacquered the 2 segments, they were resected with terminal sutures, oblique on ureteral probe "double J" tutor whose removal was conducted by cystoscopy 3 months later. The surgical follow-up was simple: removal of the JJ probe, led to the disappearance of the lumbar pain and a normal UIV. 


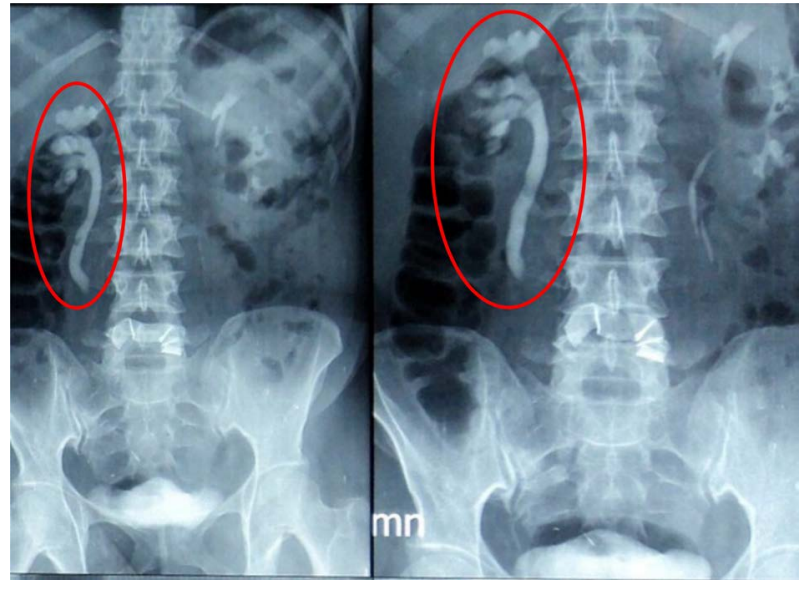

Figure 1. Inverted capital "S" image on IVU excretion image.

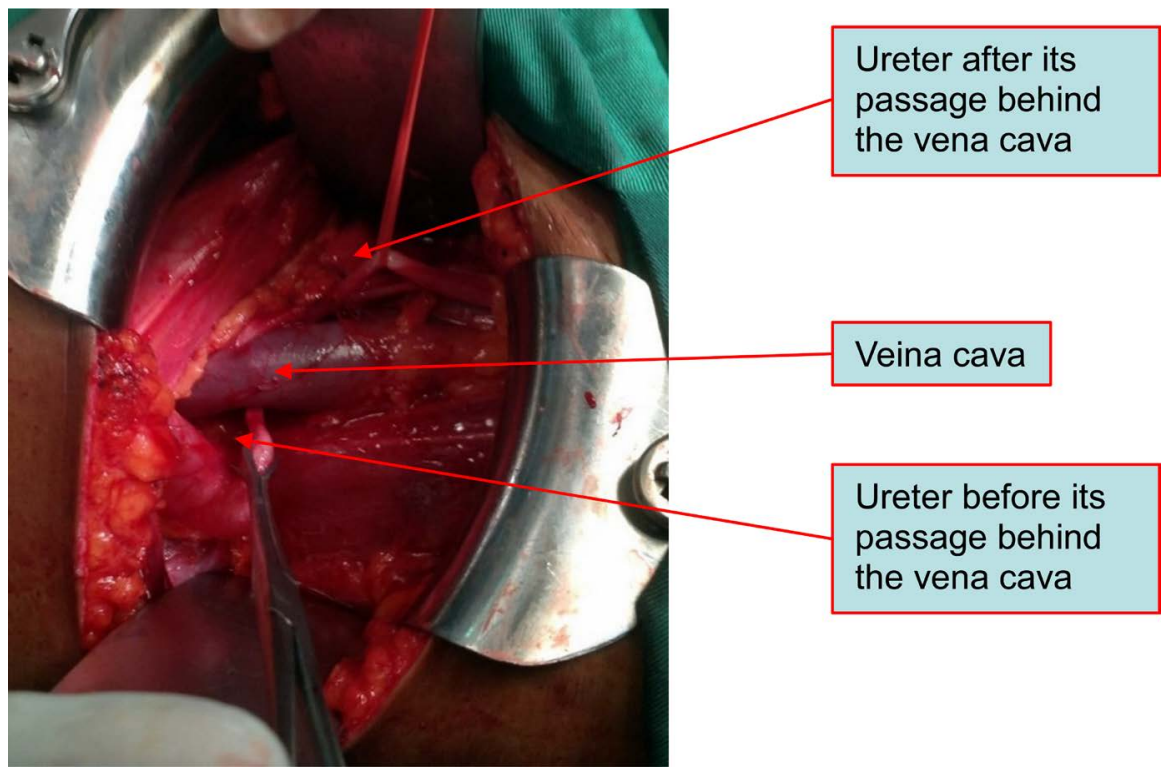

Figure 2. Intraoperative image of a retrocaval ureter of case 1.

\section{OBSERVATION 2}

M. DB, 42, had suffered right renal colic for 12 years, evolved by intermittent crisis and exacerbated by abundant alcohol consumption. The symptoms had been the subject of several unsuccessful consultations and medical treatments, after which the patient was referred to the urology unit. Physical examination found a patient in good general condition with normal hemodynamic parameters. Renal function (creatinine and blood urea) was normal. On objective ultrasound a stage III pyelocalicial dilatation was seen with a healthy parenchyma (> $3 \mathrm{~cm}$ ) without visible lithiasic obstruction. The scanner had images in favor of a retrocaval ureter [Figure 3] and the functionality of the epsilateral kidney. Patient's informed consent was obtained for the chirurgical management and the using of photographies only for scientific aim. An exploratory lumbotomy confirmed the diagnosis of retrocaval ureter during surgery [Figure 4]. A resection, decay and terminoterminal oblique anterior suture was performed on probe 


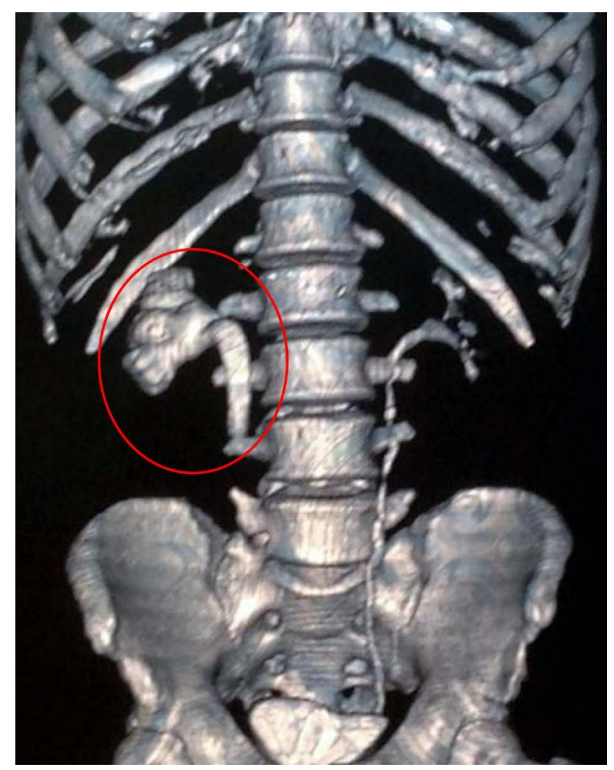

Figure 3. Image of net cessation of excretion of the contrast fluid from the ureter just before passing it from the vena cava to the scanner.

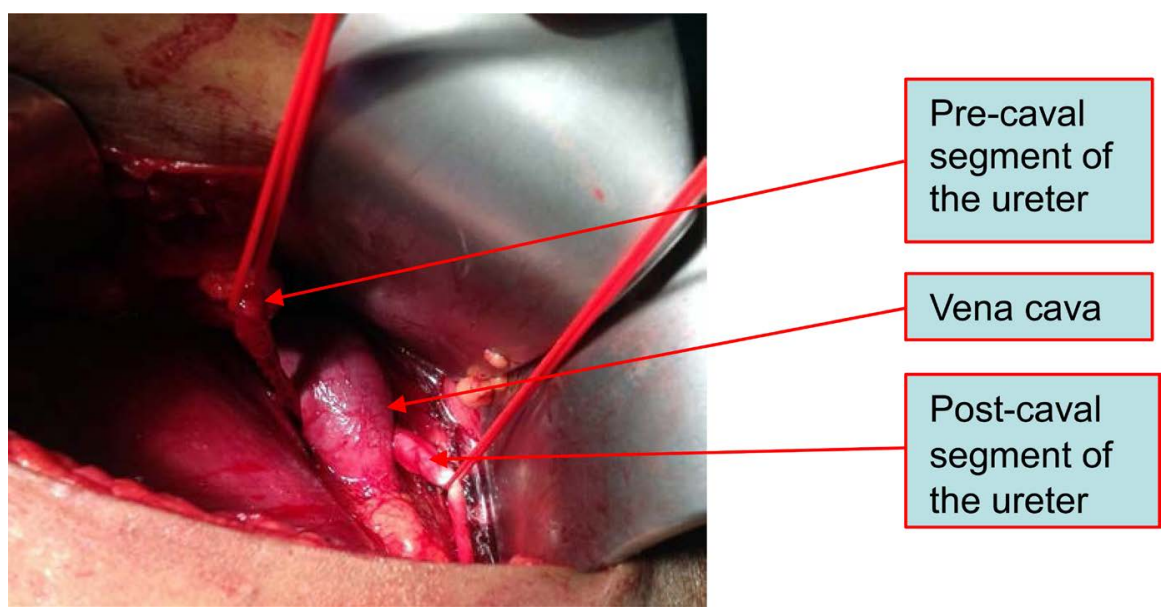

Figure 4. Intraoperative image of a retrocaval ureter of case 2.

"double J". The surgical procedure was simple while removal of the JJ probe was conducted after 3 months, resulting in the disappearance of the lumbar pain and a normal UIV.

\section{Observation 3}

M. AM, a 39-year-old working at a transportation company, had driven longdistance vehicles for over a long period of time, he quit his profession because of right exacerbated lumbar pain during and after traveling. Consultation in urology, resulted from the presence of disabling pain persistent for the past 8 years. The patient's general condition was good, hemodynamic parameters were at the limit of normal renal function. On ultrasound, presence of a right pyelocalicial stage II dilation with a good renal parenchyma was observed, whereas on the left region, the kidney was normal sized and presenting good cortico-medullary differentiation. UIV revealed a right junction syndrome with an inverted "S" right 
lumbar ureter while the contralateral kidney secreted and excreted within physiological time frames. The scanner made it possible to suspect a right retrocaval ureter. Patient's informed consent was obtained for the chirurgical management and the using of photographies only for scientific aim. A right exploratory lumbotomy confirmed the diagnosis of a type II retrocaval ureter [Figure 5]. Surgery, consisted to the resection and an end-to-end anastomosis of the ureter in front of the vena cava on probe "double J" tutor [Figure 6]. The surgical procedure was simple: removal of the JJ probe was carried out 3 months later by ultrasound, leading to the disappearance of the right lumbar pain and a normal UIV.

\section{Comment: Discussion}

Retrocaval ureter (RCU) is a rare congenital malformative anomaly with an

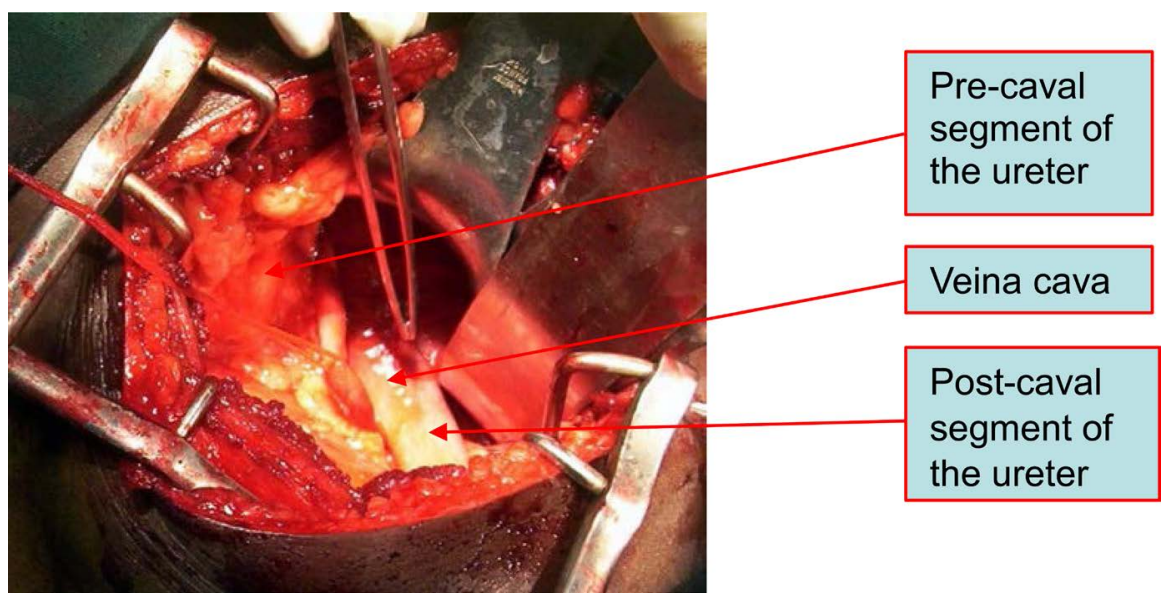

Figure 5. Intraoperative image of a retrocaval ureter of case 3.

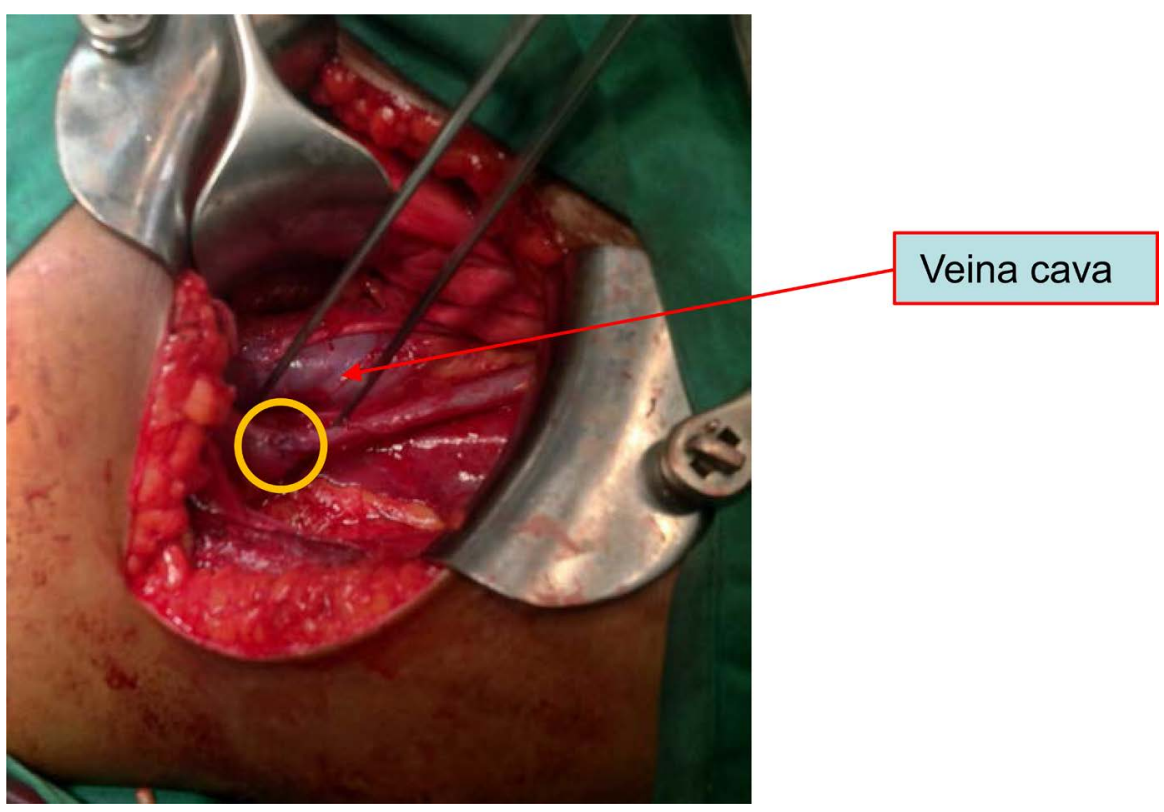

Figure 6. End-to-end anastomosis after uncrossing of the retrocaval ureter. 
incidence ranging from 0.9 to 2 per 1000 . The male sex is most affected with a sex ratio of 2.8 men to 1 woman. This prevalence is reported by several authors [2] [3] [4] [5]. This was also noted in our study, with the 3 male patients and an average age of 40 years at diagnosis. Retrocaval ureter is often the cause of multiple complications including: renal colic, urinary tract infection, renal insufficiency, lithiasis. Of all the complications, renal colic is by far the most frequent [2]-[8]. Renal colic is generally presented by intermittent crisis which may be similar to a nephrotic syndrome as the attacks are close and very unbearable. Our three patients suffered from years of renal colic that led to unsuccessful multiple consultations and medical treatments. Failure in the medical treatment of renal colic justifies initiation of a morphological assessment, in this case: ultrasound, UIV and scanner whose results must be the subject of rigorous interpretation.

Ultrasonography often reports a pyelo-calicial dilation when performed during renal colic attacks, it may be normal and should not interrupt the continuation of the examinations. It should be noted that the results gotten from ultrasound performed during or away from the crisis may be discordant from that performed away from the renal colic crisis. UIV, besides its advantage in providing information on the functions of the left epsilateral kidney, provides two crucial information, on adequate interpretation of the images. An opacification of right ureter reversed in S majuscule and an upstream pyelocalyceal dilation of the ureter. The scanner's superior imaging confirmed the UIV's results with better clarity. In medically advanced countries where MRI is easily accessible, diagnosis is even easier.

The treatment of CRU is surgical and dictated by renal colic pain intensity especially when pain is unbearable and may lead to a decrease in the patients' activities. Open surgery, though presenting satisfactory results should give way to minimally invasive surgery like laparoscopy, where available [7]-[14].

\section{Conclusion}

Retrocaval ureter is a rare congenital malformation often encountered in the male sex. The clinical symptoms are dominated by right renal colic affecting elderly patients generally between the ages of 30 and 40 years. Medical Imagery such as, ultrasound, intravenous Urography, CT scanning and MRI, are major contributions to diagnosis. Radical surgical treatment, formerly known as open surgery, must give way to minimally invasive surgery presented by laparoscopy, where available.

\section{References}

[1] Hochstetter, F. (1893) Beitrage zur entwicklungsgeschichte des venen-systems der amnioten: III. [Contribution to the Developmental History of the Vein System of Amniotes: III.] Sauger Morph Jahrb, 20, 542-542.

[2] Kakanou, A., Nchimi, A., Ghuysen, M.S., Khamis, J. and Khuc, T. (2001) Uretère rétrocave chez un enfant de dix ans. [Retrocaval Ureter in a 10-Year-Old Boy.] An- 
nales de Chirurgie, 126, 156-158. https://doi.org/10.1016/S0003-3944(00)00481-8

[3] Tembely, A., Diarra, A., Berthé, H., Diakité, M.L. and Ouattara, K. (2014) Uretere Retrocave: Deux Nouvelles Observations à L'hôpital Du Point G A Bamako. [Uretere Retrocave: Two New Observations at Point G Hospital in Bamako.] African Journal of Urology, 20, 104-107. https://doi.org/10.1016/j.afju.2013.11.007

[4] Hadzi-Djokic, J., Basic, D., Dzamic, Z., Aćimovic, M. and Markovic, Z. (2009) Uretère rétrocave: à propos de 16 cas. [Retrocaval Ureter Based on a Series of 16 Cases.] Progrès en Urologie, 19, 33-38. https://doi.org/10.1016/j.purol.2008.09.047

[5] Ichikawa, T., Kawada, S., Yamashita, T., Niwa, T., Iino, M., Koizumi, J., et al. (2014) A Case of Right Double Inferior Vena Cava with Circumcaval Ureter. Japanese Journal of Radiology, 32, 421-424. https://doi.org/10.1007/s11604-014-0312-2

[6] Muthusami, P. and Ramesh, A. (2013) Appearances of the Circumcaval Ureter on Excretory Urography and MR Urography: A Single-Center Case Series. Indian Jounal of Radiology and Imaging, 23, 81-85. https://doi.org/10.4103/0971-3026.113621

[7] Ratkal, J.M., Jadhav, R. and Naique Dessai, R.R. (2016) Circumcaval Ureter-The Paradigm Shift in Diagnosis and Management. Indian Journal of Surgery, 78, 37-40. https://doi.org/10.1007/s12262-015-1352-2

[8] Bhattacharjee, S., Sanga, S., Gupta, P. and George, R.A. (2016) Retrocaval Ureter or Preureteral Vena Cava: Lest We Forget This Rare Cause of Hydronephrosis. Medical Journal Armed Forces India, 72, 77-79.

https://doi.org/10.1016/j.mjafi.2016.08.004

[9] Li, H.Z., Ma, X., Qi, L., Shi, T.P., Wang, B.J. and Zhang, X. (2010) Retroperitoneal laparoscopic ureteroureterostomy for retrocaval ureter: report of 10 cases and literature review. Urology, 76, 873-876. https://doi.org/10.1016/j.urology.2009.12.056

[10] Zhang, J., Liu, B., Song, N., Hua, L. and Wang, Z. (2014) Retroperitoneal Laparoscopic Ureteroureterostomy for Retrocaval Ureter: A Report of 15 Cases. Surgical Practice, 18, 37-41. https://doi.org/10.1111/1744-1633.12045

[11] Cardoza, F., Shambhulinga, C.K. and Rajeevan, A.T. (2016) Retrocaval Ureter and Contra Lateral Renal Agenesis-A Case Report and Review of Literature. International Brazilian Journal of Urology: Official Journal of the Brazilian Society of Urology, 42, 842-844. https://doi.org/10.1590/S1677-5538.IBJU.2015.0549

[12] Tengue, K., Botcho, G., Kpatcha, T.M., Adabra, K., Sewa, E., Leloua, E., et al. (2016) Prise en charge de l'uretère rétrocave au Togo: A propos de 3 observations (Management of the Retrocaval Ureter in Togo about 3 Cases.] African Journal of Urology, 22, 279-283. https://doi.org/10.1016/j.afju.2016.03.008

[13] El Harrech, Y., Ghoundale, O., Kasmaoui, E.H. and Touiti, D. (2016) Transperitoneal Laparoscopic Pyelopyelostomy for Retrocaval Ureter without Excision of the Retrocaval Segment: Experience on Three Cases. Advances in Urology, Article ID 5709134, 4 p. https://doi.org/10.1155/2016/5709134

[14] Kumar, S., Singh, S. and Garg, N. (2015) Right Sided Double Inferior Vena Cava with Obstructed Retrocaval Ureter: Managed with Single Incision Multiple Port Laparoscopic Technique Using "Santosh Postgraduate Institute Tacking Ureteric Fixation Technique”. Korean Journal of Urology, 56, 330-333.

https://doi.org/10.4111/kju.2015.56.4.330 